\title{
Being a change agent in a (post-) COVID South Africa
}

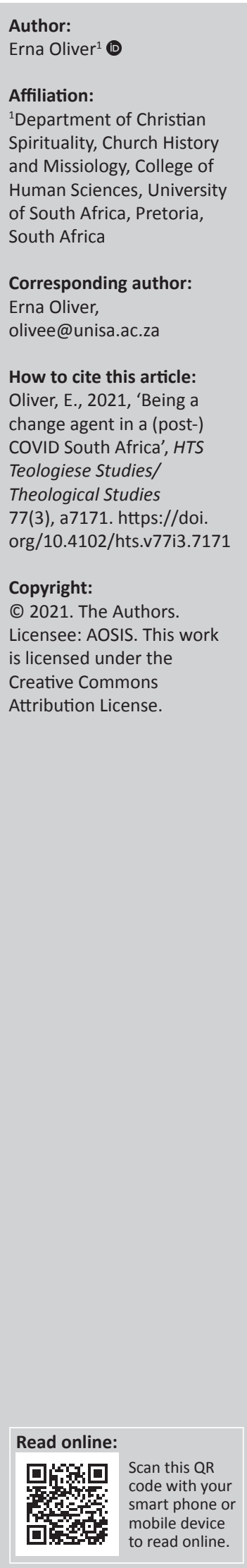

Five years have already passed since the Protestant world celebrated the quincentenary of the Reformation. It is strange, when we look back at what we have written just five years ago, how our own words and thoughts, through a retrospective lens, have gained or changed meaning. The preface to the first edition of the Special Collections on the Change Agency Project started like this (Makhanya \& Oliver 2017): ${ }^{1}$

The speed with which things change makes it clear that we are at a turning point in history. The change that society is experiencing is not an event that will soon stop and allow us to settle down. It is a complex, accelerating process with no defined destination and it often seems as if we are unable to manage it; that society is experiencing a change speed wobble. To counter this, we need to develop a mindset that is receptive to change, transformation and development. We should embrace the energy, excitement and increased productivity that allow change to enable us to rediscover our sense of adventure, inspiration and purpose for living. (p. 9)

Our lives changed dramatically and beyond expectation when the coronavirus disease 2019 (COVID-19) struck South Africa in early 2020. More than before, the need for agents of positive change and strong faith leadership is prevalent and imperative in all aspects of life and work: confirming that the Change Agency Project was initiated in time to prepare people's minds and behaviour towards the enormous challenges we are currently facing. This is clear when we look at the themes that were chosen for the five Special Collections. In 2017, the project started with The Reformation, Transformation and Change Agency, followed in 2018 with Change Agency in a 21st-century South Africa and in 2019 with The Church in Need of Change (Agency). The 2020 theme of Christianity as a Change Agent in the Fourth Industrial Revolution World was set in 2019 before the pandemic struck, and we were thrown into another kind of revolution; however, we still managed to publish the Special Collection on time during the lockdown. The final theme of 2021, Being a Change Agent in a (Post-) COVID South Africa, expresses the undefeatable hope and faith for a bright future in South Africa. The Change Agency Project produced more than 50 articles from scholars at five South African universities, as well as two international scholars. Non-academics and even undergraduate students also contributed from their real-life experiences and contributions of positive change in their communities.

Although this series of Special Collections end this year, we hope that everyone who has contributed during the past five years will continue to develop new paradigms, models and ways to bring positive change, hope and vision to society.

My deepest gratitude and acknowledgement for the opportunity to publish this Special Collection series goes to Prof. Andries van Aarde, Editor-in-chief of HTS Theological Studies. And to Willem Oliver, the corresponding editor, for his commitment, hard work and unstoppable enthusiasm to drive the project for the past five years. It is with great appreciation that I thank the authors for their contributions that made these publications inspirational and positive contributions towards the betterment of society through hope and faith. 